\title{
O incêndio do MAM-RJ e as respostas de Mário Pedrosa às crises artísticas, museológicas $\mathrm{e}$ políticas da época
}

\author{
André Leal ${ }^{1}$ \\ Recebido em setembro de 2020 \\ Aceito em dezembro de 2020
}

\begin{abstract}
RESUMO
O incêndio do MAM-RJ, em 1978, foi o maior desastre patrimonial brasileiro até aquele momento, destruindo praticamente todo seu acervo. Ao acompanharmos os escritos e a atuação do crítico de arte Mário Pedrosa antes e depois do incêndio, muitas de suas ideias sobre arte e curadoria vêm à tona. Iremos aqui apresentar três momentos do pensamento "museal" de Pedrosa em torno desse evento: a proposta de exposição de arte indígena "Alegria de viver, Alegria de criar", prevista para o MAM-RJ antes do incêndio, sua proposta de reconstrução do museu depois do incêndio como "Museu das Origens" e sua atuação junto ao Museu da Solidariedade Salvador Allende, no Chile. Esses três eventos não apenas demonstram o pensamento museológico de Pedrosa, mas também expressam o potencial de atuação do crítico frente a diferentes momentos de esgotamentos e crises de modelos: da arte moderna e ocidental, da tragédia patrimonial e da política internacional, respectivamente.
\end{abstract}

Palavras-chave: Mário Pedrosa; arte moderna; arte contemporânea; experimental.

\section{The MAM-RJ fire and Mário Pedrosa's answers to the artistic, museological and politic crises of the period}

\begin{abstract}
The great fire of the MAM-RJ, in 1978, was the biggest Brazilian patrimonial disaster until that moment, destroying almost its entire collection. As we follow the writings and practice of art critic Mário Pedrosa before and after the fire many of his curatorial and artistic ideas emerge. We will here present three moments of Pedrosa's "museal" conceptions around this event: the proposal for the indigenous art exhibition "Joy of living, Joy of creating", planned for MAM-RJ before the fire, his proposal for the reconstruction of the museum after the fire as the "Museum of Origins" and his work in creating the Salvador Allende Solidarity Museum, in Chile. These three events not only demonstrate Pedrosa's museological thought, but also express the potential of the critic's responses in face of different moments of exhaustion and model crises: of modern and western art, of heritage tragedy, and of international politics, respectively.
\end{abstract}

Keywords: Mário Pedrosa; modern art; contemporary art; experimental.

\section{El incendio del MAM-RJ y las respuestas de Mário Pedrosa a las crisis artísticas, museológicas y políticas de la época}

\footnotetext{
${ }^{1}$ Doutorando em Artes Visuais no PPGAV/EBA/UFRJ, Rio de Janeiro, Brasil; bolsista FAPERJ Nota 10. Faz parte da Rede Solidária de Pesquisadores do Arquivo do Museu da Solidariedade Salvador Allende. Email: coxaleal@gmail.com
} 


\section{RESUMEN}

El incendio del MAM-RJ, en 1978, fue el mayor desastre patrimonial brasileño hasta entonces, destruyendo prácticamente toda su colección. A medida que seguimos los escritos y la actuación del crítico de arte Mário Pedrosa antes y después del incendio, muchas de sus ideas sobre el arte y la curaduría pasan a primer plano. Aquí presentaremos tres momentos del pensamiento "museístico" de Pedrosa en torno a este evento: la propuesta de la exposición de arte indígena "Alegría de vivir, Alegría de crear", prevista para el MAM-RJ antes del incendio, su propuesta de reconstrucción del museo después del incendio como "Museo de los Orígenes" y su actuación en el Museo de la Solidaridad Salvador Allende, en Chile. Estos tres hechos no solo demuestran el pensamiento museológico de Pedrosa, sino que también expresan el potencial de la actuación del crítico ante diferentes momentos de agotamiento y crisis de modelos: del arte moderno y occidental, de la tragedia patrimonial y de la política internacional, respectivamente.

Palabras-clave: Mário Pedrosa; arte moderno; arte contemporâneo; experimental.

\section{Introdução}

Na madrugada de 8 de julho de 1978 o Museu de Arte Moderna do Rio de Janeiro (MAM-RJ) foi tomado por um incêndio que consumiu praticamente todo seu acervo com obras de renomados artistas nacionais e internacionais, encerrando um ciclo de experimentações artísticas que ali ocorriam desde a inauguração de sua sede definitiva no Aterro do Flamengo em $1958 .^{2}$ O crítico de arte Mário Pedrosa, que havia acabado de voltar de seu segundo exílio, estava organizando, junto com a artista Lygia Pape e equipe interdisciplinar, a exposição de arte indígena “Alegria de viver, Alegria de criar”, que iria ocupar os três pisos do museu no início de 1979. Tratava-se de uma incipiente e inédita tentativa decolonial de inserir a produção indígena no circuito artístico da época em pé de igualdade com a produção artística moderna e contemporânea. Sendo sobretudo uma forma de reparação histórica com as populações indígenas dizimadas desde a invasão portuguesa (PEDROSA, 1981b, p. o9), era também uma resposta de Pedrosa e de Pape ao que identificavam como um esgotamento das possibilidades da arte moderna, e ocidental, de modo geral.

\footnotetext{
${ }^{2}$ O edifício-sede do MAM-RJ, projetado por Affonso Eduardo Reidy, foi inaugurado em etapas entre 1958 e 1967. A partir de então ali se estabelece um importante polo de arte experimental, com viés também pedagógico e político, sendo um importante refúgio da repressão do governo ditatorial instalado no país a partir do golpe militar de 1964. Para maiores informações sobre o MAM-RJ nas décadas de 1960 e 1970, ver: GOGAN, Jessica (org.); MORAIS, Frederico. Domingos da criação: uma coleção poética do experimental em arte e educação. Rio de Janeiro: Instituto MESA, 2017. E LOPES, Fernanda. Área experimental: lugar, espaço e dimensão do experimental na arte brasileira dos anos 197o. São Paulo: Prestígio editorial, 2013.
} 
Após o incêndio do museu, Pedrosa propôs que este fosse transformado no "Museu das Origens", composto por cinco museus: de arte negra, indígena, popular, "virgem" (do inconsciente), e moderna e contemporânea, orbitando ao redor de um núcleo “criativo e experimental” (PEDROSA, 1978b). Tais museus demarcariam as matrizes históricas da arte contemporânea brasileira ativas no presente. A proposta também revela as transformações no pensamento do crítico frente ao que ele identificava como o esgotamento da arte moderna e aos impasses gerados tanto pelo incêndio do MAM-RJ, quanto pela situação da política cultural brasileira à época.

Alguns anos antes, entre 1971 e 1973, Pedrosa esteve à frente da criação do Museu da Solidariedade no Chile, reunindo centenas de obras doadas por importantes artistas internacionais em apoio à "via chilena do socialismo" de Salvador Allende. Como resposta aos ataques da direita nacional e internacional ao governo Allende e à crise política por eles gerada, pensou-se na criação de um museu de arte moderna e experimental que demonstrasse o apoio dos artistas ao governo chileno. A passagem de Pedrosa pelo Chile também informa mudanças de postura pela qual o pensamento do crítico passou na década de 1970.

Tratam-se, portanto, de três momentos da fase tardia da carreira de Pedrosa, nascido em 1900 em Pernambuco e falecido em 1981 no Rio de Janeiro, que indicam as saídas propostas pelo crítico para três diferentes crises - das artes, patrimonial e política -, mas que reúnem e conjugam diferentes aspectos de seu pensamento ao longo das mais de quatro décadas de carreira como crítico e curador. Iremos debater também textos anteriores de Pedrosa que informam ou contradizem os eventos em questão, apresentando as vicissitudes de uma carreira tão longeva e plural, mas diretamente relacionadas com os desdobramentos artísticos e políticos de seu tempo. Assim, é possível identificar nesses eventos diferentes aspectos de um período registrado por muitos pesquisadores como de passagem entre o "moderno" e o "contemporâneo".

Cabe ressaltar que dentre as contradições expressas nos escritos de Pedrosa a que mais nos interessa neste ensaio é sua relação com a produção indígena, presente nas propostas expositivas “Alegria de viver, Alegria de criar" e no "Museu das Origens”. Em sua trajetória, o crítico oscila entre duas visões conflitantes em relação a essa produção, mas que se atravessam no decorrer dos anos. Até a década de 1970 poucas vezes Pedrosa 
a vê como algo a ser mobilizado no presente; a produção indígena seria parte de um passado anterior à invasão portuguesa e o Brasil não teria uma cultura prévia digna de valor. Ao longo da década de 1970, e principalmente após sua passagem pelo Chile como veremos, ele mobiliza essa produção no presente, como na exposição "Alegria de viver, Alegria de criar", entendendo o modo de produção dos indígenas como exemplo para os artistas experimentais da época. A produção indígena, portanto, é vista como modelo de produção estética dentro de uma sociedade não-capitalista, apesar de Pedrosa abordála muitas vezes ainda de modo abstrato e como parte de um presente a-histórico. ${ }^{3}$ Para fins analíticos apresentamos esses dois momentos na trajetória de Pedrosa de modo um tanto esquemático, mas é importante frisar que ambas as atitudes do crítico frente à produção indígena se interpenetram e não se deixam reduzir a esquematismos, fazendo parte da complexa trama de produções mobilizada por Pedrosa em seus escritos ao longo de sua vida. Assim, sua sensibilidade lhe permitiu abordar, ainda em sua fase mais radicalmente modernista, produções desviantes dos cânones consagrados, bem como posteriormente ele continua sendo um homem de seu tempo e não leva a inclusão da produção indígena à radicalidade contemporânea de seu estatuto de objetos produzidos no presente, como atualmente se vê em alguns museus e exposições pontuais, algo que pretendemos deixar mais claro ao longo do texto.

\subsection{Crise artística: impasses da arte moderna e o pós-modernismo experimental}

As décadas de 1960 e 70 são vistas por muitos pesquisadores como um momento de inflexão na produção artística ocidental, de passagem do "moderno" para o “contemporâneo" (REINALDIM; SOMMER, 2020, p. 91). Mesmo tendo uma atuação essencialmente modernista em sua linguagem e também estreitamente ligada à produção artística e arquitetônica dos modernismos brasileiros, Mário Pedrosa foi um dos primeiros a captar o que identificou em diversos textos como um "esgotamento" da

\footnotetext{
${ }^{3}$ ver a esse respeito a pesquisa de mestrado de Pollyana Quintella, na qual ela analisa a questão do "primitivismo" em Mário Pedrosa, com foco principal justamente nas propostas expositivas aqui abordadas: QUINTELLA, 2018.
} 
arte moderna e já em 1966 denominou a produção ambiental de Hélio Oiticica de "pósmoderna”, muito antes do termo se tornar corrente.

Em “Arte ambiental, arte pós-moderna, Hélio Oiticica”, Pedrosa indica o que seria uma passagem das questões materiais e perceptivas do modernismo para questões culturais e sociais mais amplas, e a produção de Oiticica daria a ver tal movimento. Segundo o crítico, estaríamos "agora em outro ciclo, que não é mais puramente artístico, mas cultural, radicalmente diferente do anterior", inaugurado pelas Demoiselles d'Avignon (1907) de Picasso. "Nessa fase de arte na situação, de arte antiarte, de 'arte pósmoderna' [...] os valores propriamente plásticos tendem a ser absorvidos na plasticidade das estruturas perceptivas e situacionistas" (PEDROSA, 1966a, s/p). 4

Pedrosa identifica na produção de Oiticica uma série de pontos que resumem também ideias que tinha em relação à produção artística de modo geral, reunindo sua visão política, marcadamente marxista, a importância que dava à teoria da gestalt para a percepção artística e as preocupações sociais e biográficas que sempre informaram sua produção crítica. 5 Segundo Pedrosa (1966a, s/p), na "arte ambiental" de Oiticica, "nada é isolado" e "o conjunto sensorial domina", algo que o artista havia absorvido em sua vivência no morro da Mangueira. O Bólide em homenagem a Cara de Cavalo, criminoso assassinado brutalmente pela milícia Scuderie Le Cocq, também era outro momento dessa nova etapa artística, pois seria "verdadeiro monumento de autêntica beleza patética, para a qual os valores plásticos por fim não foram supremos. [...] Aqui é o conteúdo emocional que absorve o artista" (PEDROSA, 1966a, s/p). Portanto, as questões levantadas pela produção de Oiticica em particular, mas também de outros artistas "experimentais", corresponderiam a temas muito mais amplos que aqueles estritamente artísticos colocados pelas vanguardas modernistas, podendo assim ser caracterizadas como pós-modernas.

Em outro texto do mesmo ano, Pedrosa realizaria uma leitura fundamentalmente marxista das condições da produção artística daquele momento, que desdobram pontos apresentados acima. No artigo “Crise do condicionamento artístico”,

\footnotetext{
${ }^{4}$ buscamos aqui citar o máximo possível as fontes primárias dos textos críticos de Pedrosa, a maioria publicados em jornais diários e revistas.

5 Ver: PÉREZ-BARREIRO, 2017.
} 
o crítico afirma que, frente aos desenvolvimentos tecnológicos recentes, o estilo já não teria preponderância na produção industrial e artística. Faltariam "as qualidades artesanais de perenidade e similitudes intrínsecas para criar unidade formal e estilística”, além da "solidez de profundas tradições culturais capazes de fornecer o estrume para uma criação coletiva super individual" (PEDROSA, 1966b, p. 10), levando os artistas e a indústria a se submeterem aos caprichos sempre cambiantes do mercado de consumo. Essa falta de "padrões preexistentes” também indicaria “que a Arte perdeu suas raízes culturais, e foi subordinada a outros padrões necessariamente instáveis e aleatórios como os dominantes no mercado consumidor" (PEDROSA, 1966b, p. 10). Mais uma vez, Pedrosa conclui identificando uma nova atitude dos artistas frente à sua produção, que já não poderia ser incluída nos modelos modernistas. Para o crítico, estaríamos diante de "um fenômeno cultural e mesmo sociológico inteiramente novo", que fugiriam "dos parâmetros do que se chamou de arte moderna. Chamai a isso de arte pós-moderna, para significar a diferença” (PEDROSA, 1966b, p. 10).

Em 1967, Pedrosa escreveria o artigo "Mundo em crise, homem em crise, arte em crise", no qual aprofunda sua análise da nascente "sociedade de consumo espetacular" (LEAL, 2015, p. 65) e as possibilidades de alienação ou de emancipação que esta nova situação permitiria, sempre movida pelos avanços tecnológicos. Segundo o crítico, "para vencer a defasagem entre o acúmulo das transformações tecnológicas no presente e o isolacionismo de fundo artesanal, não se vê, hoje, outro recurso senão em tudo projetar, seja no domínio científico, técnico ou estético, em termos ambientais" (PEDROSA, 1967, p. 3). Em sentido similar ao que colocara, em 1966, em relação às pressões exercidas pelo mercado sobre os artistas, Pedrosa (1967, p. 3) segue afirmando que "nessa grave encruzilhada em que se encontra a arte, o artista é excitado por mil solicitações, vindas do mundo ambiente, cada vez mais amplo, mais complexo e surpreendente”, daí também a exigência da arte em se reintegrar ao ambiente de modo geral.

Se nestes textos podemos acompanhar as transformações pelas quais o campo artístico estava passando nesse momento de transição do "moderno" para o “contemporâneo”, Pedrosa já havia apresentado uma visão sobre a produção artística em termos muito mais amplos que aqueles rigorosamente modernistas em 1947, em uma 
conferência que teve o sugestivo título de "Arte, necessidade vital”. Proferida na abertura da exposição de pinturas dos usuários do Setor de Terapêutica Ocupacional do Centro Psiquiátrico Nacional de Engenho de Dentro, no Rio de Janeiro, comandado por Nise da Silveira, Pedrosa busca apresentar seu modelo de concepção artística como inerente à humanidade, afastando-se das concepções acadêmicas e do primeiro modernismo brasileiro então vigentes no país. Essa postura também está relacionada à sua tentativa de ampliação do campo artístico para o abstracionismo, que vigoraria nas décadas seguintes e cujo ápice foram os movimentos concreto e neoconcreto nos quais Pedrosa teve participação fundamental.

Contrapondo-se aos excessos regulatórios e intelectuais do academismo e explorando o papel do inconsciente na produção dos artistas - profissionais ou não -, o crítico defende a abertura do campo artístico para produções "desviantes" como as das crianças, dos povos "primitivos", além da dos internos de hospitais psiquiátricos como o do Engenho de Dentro. Segundo Pedrosa (1947, s/p), “a atividade artística é uma coisa que não depende [...] de leis estratificadas, frutos da experiência de apenas uma época na história da evolução da arte", mas se estenderia "a todos os seres humanos". Para ele, "a vontade de arte se manifesta em qualquer homem de nossa terra, independente do seu meridiano, seja ele papua ou cafuzo, brasileiro ou russo, negro ou amarelo, letrado ou iletrado, equilibrado ou desequilibrado".

A "necessidade vital" de criação artística escaparia, portanto, às regras intelectuais elaboradas desde o Renascimento e as "modernas teorias psicológicas" confirmariam isso. Para Pedrosa (1947, s/p), "cada indivíduo é um sistema psíquico à parte, e também uma organização plástica e formal em potência”. Assim, o fenômeno artístico teria que "ser entendido num sentido mais amplo que até ontem" (PEDROSA, 1947, s/p), chancelando nos círculos for mais das artes a exposição instalada no salão do Ministério da Educação e Saúde, símbolo do modernismo arquitetônico brasileiro e que já tinha abrigado e abrigaria muitas outras exposições de arte moderna. Para Pedrosa, a arte seria "a linguagem das forças inconscientes que atuam dentro de nós" (PEDROSA, 1947, s/p). Vemos, assim, que o crítico já buscava dar um sentido mais abrangente à arte, além dos círculos estreitos de iniciados, e a experiência com os internos do Engenho de Dentro lhe abriu os olhos para produções que escapavam a esses círculos. 
Outra indicação dessa visão ampliada da produção artística que Pedrosa tinha está na citação à produção de "povos primitivos", mesmo que ainda tratados como parte de um passado arqueológico ou como uma cultura mais atrasada que a ocidental. Desde um ponto de vista bastante eurocêntrico, Pedrosa (1947, s/p) afirma que reconhecer "os povos bárbaros da América pré-colombiana, da Oceania, da África” como produtores de arte digna de interesse faz com que esta deixe "de ser privilégio de raças superiores da Europa ocidental”. Assim, “a arte não é mais produto de altas culturas intelectuais e científicas. Povos primitivos também a fazem” e seus "produtos artísticos [...] são formalmente tão legítimos e bons quanto os das civilizações super-requintadas da Grécia ou da França” (PEDROSA, 1947, s/p). Apesar dessa sua visão ainda muito calcada na experiência ocidental, vemos que há um esforço do crítico em incorporar essas produções no circuito artístico formal, como estava a fazer com os internos do hospital psiquiátrico. Tardariam algumas décadas, porém, para que Pedrosa ampliasse esse esforço e vislumbrasse a produção indígena como possível saída para os impasses do modernismo por ele identificados, mesmo que essa saída ainda contivesse suas próprias contradições, como veremos adiante.

Mário Pedrosa foi também um entusiasta da arquitetura moderna brasileira e viu em Brasília o ápice de sua realização, o termo final de sua profética frase de que o Brasil seria um país “condenado a ser moderno” e também a culminação de sua ideia da arquitetura moderna como síntese das artes. Muitas contradições estão presentes nessa linha de raciocínio, nas quais não iremos adentrar aqui senão na que nos interessa para o presente debate: a condenação ao moderno era também fruto de sua ideia do Brasil como um país colonizado e sem passado próprio. Segundo Pedrosa, o Brasil teria "vindo à civilização" com a chegada dos portugueses. Assim,

\footnotetext{
nosso passado não é fatal, pois nós o refazemos todos os dias. E bem pouco preside ele ao nosso destino. Somos, pela fatalidade mesma de nossa formação, condenados ao moderno. A nossa 'modernidade' é tão radical que, coisa rara entre os Estados, temos a certidão do nosso batismo. Nascemos numa data precisa: 22 de abril de 1500. Antes disso simplesmente não existíamos (PEDROSA, 1959, p. 3, grifo do autor).
} 
Pedrosa segue descrevendo a formação nacional em termos quase neutros em relação à exploração da mão de obra negra escravizada e ignorando a presença indígena por aqui. Seu entusiasmo com a construção de Brasília, além das questões formais da arquitetura e do urbanismo modernistas de Costa e Niemeyer, se encaixava também em sua visão marxista de uma dialética que levaria a uma melhoria das condições sociais e geográficas do país, fugindo à trajetória extrativista que sempre marcou - e continua marcando - a ampliação das fronteiras agrícolas brasileiras. Segundo Pedrosa (1981a, p. 307), a solução de Lucio Costa, aceitaria as contradições nacionais, no caso a falta de um efetivo planejamento regional anterior à construção da nova capital, e reconhece que "a solução possível ainda era na base da experiência colonial, quer dizer, uma tomada de posse à moda cabralina, chanfrando na terra o signo da cruz". A instalação da capital no coração do Brasil poderia então ser encarada como um processo de autocolonização de nosso território, fruto do "espírito do plano" (PEDROSA, 1959, p. 3) que marcaria a época, permitindo o desenvolvimento do interior do país. Para tanto, porém, seria fundamental a realização da reforma agrária, que como sabemos nunca foi levada adiante no Brasil.

\subsection{Alegria de viver, alegria de criar: a saída indígena}

Em uma produção extensa como a de Pedrosa, é possível acompanharmos as transformações no pensamento exposto pelo crítico em suas críticas nos jornais da época e no debate público de modo geral. Assim, se nas décadas de 1940 e 50 ele via os indígenas brasileiros como "povos primitivos" de um passado anterior à invasão portuguesa, anos mais tarde ele buscaria apresentar a produção estética desses povos em pé de igualdade com a produção ocidental justamente no MAM-RJ, mesmo que muitas vezes ainda trate a produção indígena de modo abstrato e como parte de um passado pré-histórico. Segundo o crítico, depois de sete anos de exílio no Chile e na França, "uma nostalgia imensa da nação brasileira" o invadiu quando visitou a Amazônia peruana (PEDROSA, 1977, s/p). Ali também tomou consciência da necessidade de se dirigir às tragédias do genocídio indígena e da destruição da floresta amazônica. Recuperar a produção indígena, portanto, ia ao encontro tanto de questões políticas 
urgentes, quanto da necessidade de ampliação do campo artístico face ao esgotamento do modernismo apontado pelo crítico. Como afirmou Pedrosa (1977, s/p) na mesma entrevista a Casimiro Xavier de Mendonça, frente à "crise profunda" da arte moderna devida à "crise geral do mundo", ele queria "mostrar para essa meninada, este outro lado, esse trabalho dos índios, esse mundo onde os valores são outros e têm este prazer no fazer e no criar".

Assim, Pedrosa propôs, junto com uma série de artistas, antropólogos e arqueólogos, a exposição "Alegria de viver, Alegria de criar". Essa exposição iria reunir centenas de peças indígenas no MAM-RJ no início de 1979, mas o incêndio do museu interrompeu sua produção. A exposição contava com curadoria adjunta da artista Lygia Pape, cuja dissertação de mestrado "Catiti Catiti na terra dos Brasis", defendida em julho de 1980, teve "como tema o problema da crise da arte no mundo contemporâneo" (PAPE, 1980, p. o1) e, apoiando-se nos escritos de Mário Pedrosa, indicava o "artista-inventor" e o modelo de produção estética dos indígenas brasileiros como saída para tal crise. A equipe de pesquisa da exposição também incluía a museóloga Tereza Bauman, os antropólogos Berta Ribeiro e Eduardo Viveiros de Castro; a iconografia seria realizada pelas artistas Maureen Bisilliat e Claudia Andujar e a programação visual estaria a cargo do artista Aloísio Carvão. Nos arquivos de Pedrosa na Biblioteca Nacional há um extenso levantamento das obras que já haviam sido mapeadas pelos pesquisadores em museus nacionais e internacionais, incluindo o manto Tupinambá de uma coleção dinamarquesa, além de um orçamento detalhado dos custos da exposição. Como a exposição não iria poder circular em outras localidades devido à complexidade logística, seria realizado um documentário para divulgá-la país afora. De acordo com as notas de Pedrosa, uma oca seria construída no térreo do MAM-RJ e seriam reunidas 1563 peças, divididas entre brinquedos, plumária, artefatos de miçanga, cerâmica, tecidos e trançados e peças arqueológicas (PEDROSA, 1978a).

Nas notas há também um esboço do texto de apresentação da "mostra de arte dos povos indígenas do Brasil" que seria "um projeto destinado a marcar época na história cultural do nosso país": 
a exposição abrangerá todos aspectos decisivos dessa arte e cultura, não só da atualidade como de seu tempo histórico e mesmo pré-histórico. [...] Esta oportunidade não se justifica apenas em função do momento cultural do Brasil, mas em função da crise do condicionamento histórico-cultural-artístico que alcança o nosso país, que alcança a América Latina em seu todo e se estende mesmo à[s] velhas metrópoles do mundo. (PEDROSA, 1978a, s/p, grifos nossos).

Tratava-se de "encontrar as raízes de nossos antepassados pré-históricos que foram certamente em linha reta os fundadores da nossa nação primeira”, assim acrescentando "nova dimensão à formação de nosso complexo cultural nacional" (PEDROSA, 1978a, s/p). Vemos que Pedrosa está buscando incorporar a produção indígena na historiografia da arte brasileira, bem como em rever o papel dessas populações no presente, contando inclusive "com a colaboração viva e indispensável dos índios xinguanos" (PEDROSA apud SOMMER, 2020, p. 129). A produção indígena, além de seu papel histórico, seria também exemplo para o artista-inventor na reintegração da criação artística às práticas vitais como saída para o impasse da arte moderna e sua inserção na sociedade contemporânea livre das amarras do mercado. Segundo Pedrosa (1981b, p. 09), a arte plumária seria “onde o índio mostra as qualidades de um artista sem saber que é artista, de um homem que vive na sua comunidade e, apesar de todas as pressões de fora, mantém sua individualidade, embora histórica e socialmente esteja condenado a desaparecer". A exposição teria, portanto, "esse caráter de reposição histórica, moral, política e cultural”, já que "temos uma dívida para com esta raça, a primeira, a matriz, que constitui a formação do Brasil”.

É importante frisar, porém, que apesar da menção aos índios xinguanos indicada acima, Pedrosa raramente nomeia diretamente os povos que participariam da mostra, e a maioria das peças elencadas pelos curadores viria de coleções já existentes. Também transparece de um modo geral um interesse maior do crítico pelo contexto de produção dos povos indígenas do que pelas suas características formais ou estéticas propriamente, sendo este contexto - a estereotipada "alegria de viver" de um povo pristino - um modelo para o artista experimental de sua época. Como afirma Pollyana Quintella (2018, p. 40), a atuação de Pedrosa está "longe de qualquer experiência etnográfica ou de um exercício de teorização sistemática" e o crítico "recorre à arte indígena como um todo abstrato, [...] para apresentar um referencial produtivo simultaneamente próximo - como origem 
da arte brasileira - e distante, localizado num outro tempo, numa outra geografia”. Ou seja, há um duplo movimento de abstração dessas populações que Pedrosa realiza, apesar de seu louvável e precursor esforço em incorporar a produção indígena à história da arte brasileira: os povos indígenas são reconhecidos como precursores de nossa cultura, mas ao mesmo tempo estariam fadados ao desaparecimento dentro do “progresso capitalista”.

Fica claro, portanto, que o que interessava ao crítico em última instância era o contexto de produção da arte indígena brasileira como motor para uma revisão do papel das vanguardas artísticas em um presente acossado pelas tecnologias da comunicação e o status de mercadoria que tudo integra ao sistema capitalista. Argumento explicitado na mesma entrevista de Pedrosa a O Pasquim:

não posso dizer: “a Arte Moderna acabou! Viva a Arte Primitiva!”. [...] Mas as vanguardas acabaram, isto se considerarmos vanguarda aquilo que amplia o repertório. O que amplia o repertório hoje não é vanguarda, pois não amplia nada pelo qual o homem possa aumentar seu saber. No processo que está aí, a Arte não se conjuga ao que se passa no mundo. Não é vanguarda aquilo que fica de um lado da rua enquanto que do outro corre o drama do mundo de hoje (PEDROSA, 1981b, p. 9).

O incêndio do MAM-RJ, porém, interrompeu suas atividades e deixou claro que a crise das artes e da sociedade era de fato muito mais profunda. Em texto anterior ao projeto de "Alegria de viver, Alegria de criar", Pedrosa já havia analisado a importância da produção estética indígena e negra em relação à crise da arte moderna do período, em outra de suas aberturas do campo artístico a produções não-canônicas. Em "Arte dos Caduceus, arte negra, artistas de hoje”, de 1968, o crítico parte das pesquisas etnográficas de Franz Boas e Claude Lévi-Strauss para aproximar a produção desses povos “primitivos" às de artistas contemporâneos, além de se referir à importância da arte africana para a arte moderna europeia. Segundo Pedrosa (1968, p. 4), “a arte negra” havia atraído os primeiros modernistas europeus por "suas intrínsecas qualidades formais, sua estrutura hierarquizada" em contraposição a "uma escultura [...] naturalista ou naturalizante, puro amálgama de massas ou teatralidade convencional que então dominava os centros artísticos mais eminentes da Europa”. Em contraste, naquele momento, "as artes das culturas primitivas", como a dos caduceus, ou Kadiwéu, 
“exercem fascínio sobre a sensibilidade moderna pelo que significavam, pela ação que exerciam, pelo comportamento coletivo que impunham à sociedade de onde brotavam" (PEDROSA, 1968, p. 4).

Vemos novamente Pedrosa voltar sua atenção para produções não-ocidentais como resposta ao esgotamento dos preceitos modernistas e das mudanças sociais de sua época. Uma arte participativa e ativa na coletividade era o que os melhores artistas estariam produzindo, e a arte dos "primitivos" seria um momento anterior na genealogia dessa atitude artística. Ou seja, aqui é que aparece pela primeira vez em seus escritos o contexto da produção artística indígena como possível modelo para os artistas experimentais contemporâneos.

\footnotetext{
Na realidade o que torna os artistas de hoje [...] nostálgicos, no seu isolamento cultural e espiritual, é a ausência de ressonâncias culturais coletivas acima do apelo estético de sua obra. Esta não consegue vencer o isolamento, alcançar o coletivo e o mítico, através do campo solitário do gosto individual, cujo pólo contrário, é o gosto da moda (PEDROSA, 1968, p. 3).
}

Assim, para além dos valores formais dessa produção, o interesse contemporâneo estaria novamente voltado para a "atitude e o trabalho do artista negro ou do artista caduceu, nos seus respectivos contextos sociais”. Pedrosa (1968, p. 3) conclui seu texto afirmando que "o artista primitivo cria um objeto 'que participa'. $\mathrm{O}$ artista de hoje, com algo de um desespero dentro dele, chama os outros a que dêem participação ao seu objeto", como forma de fazer com que sua produção participe da sociedade de maneira mais livre que aquela imposta pelo mercado.

\subsection{Crise museológica: o incêndio do MAM-RJ}

Em 8 de julho de 1978 um incêndio de grandes proporções atingiu o MAM-RJ, destruindo quase a totalidade de seu acervo de obras nacionais e internacionais. Das cerca de mil obras da coleção do museu, apenas 50 sobreviveram e a exposição temporária que estava em cartaz, “Arte Agora III - América Latina: Geometria sensível”, com 205 obras expostas, queimou por completo, incluindo toda a fase construtiva do pintor uruguaio Joaquín Torres Garcia, verdadeira tragédia cultural para nosso vizinho 
sul-americano. A matéria que estampou a capa do Jornal do Brasil de 9 de julho dá as dimensões do desastre cultural e ecoa no século 21, dada a semelhança com o descaso que levou ao incêndio do Museu Nacional em setembro de 2018 - quase exatos 40 anos depois - e cujo combate também falhou devido à falta de pressão nas mangueiras dos bombeiros.

As chamas foram percebidas pelo vigia do museu às 3 h25m e acredita-se que tenham sido provocadas por um curto-circuito. Vinte e cinco minutos depois chegaram dois carros dos bombeiros que pouco puderam fazer, pois um tinha uma mangueira furada, conforme disse uma testemunha (JORNAL DO BRASIL, 1978, p. 1).

A tragédia interrompeu um ciclo de experimentações no MAM-RJ que seria o ápice de um momento cultural neovanguardista na cena artística nacional, mas que já vinha dando sinais de esgotamento havia alguns anos, como sentido por Mário Pedrosa. A resposta dos agentes culturais cariocas foi imediata e uma grande mobilização surgiu sobre as cinzas do museu. Um "Comitê Permanente para a Reconstrução do MAM" foi prontamente organizado e no final de semana seguinte uma grande manifestação, um ato cultural roteirizado pelo cineasta Aurélio Michiles, tomou as ruas da cidade. Acudida por diversos artistas e grupos culturais cariocas, o ato reuniu cerca de 3 mil pessoas e terminou com a atriz Bibi Ferreira lendo o documento preparado pelo Comitê.

Novamente as palavras de 1978 podem ser replicadas para o presente nacional, no qual a cultura é vista como um luxo das elites, e sofre com a carência de políticas públicas. Seria o momento das "classes dirigentes do Brasil [...] olharem para dentro de si mesmas e verem o estado de pobreza em que se encontra o seu país, o nosso país”, elencando diversos aspectos do estado de "abandono" no qual o país se encontrava, incluindo o desaparecimento de nossas florestas e dos povos originários, que viveriam como “fósseis”, “condenados a desaparecer com a 'marcha da civilização e do progresso', se um esforço gigantesco e sábio não os vier preservar.” Ademais, o fato principal relacionado ao incêndio do MAM-RJ era o de que "cultura e arte no Brasil [...] continuam a ser realidades periféricas, ilhas de luxo" pois não eram vistas como "necessidades também fundamentais de todo ser humano", recebendo "migalhas - recursos financeiros irrisórios, tardios e dispersos, gestos altruísticos esporádicos, brilhos propagandísticos, 
artifícios de retórica, rebarbas de politicagem, resíduos de ócio”, já que não tínhamos, e novamente não temos, uma política cultural sólida e de amplo alcance (A CAMPANHA, 1978, p. 10).

\subsection{O "Museu das Origens": uma história experimental da arte brasileira}

Mário Pedrosa também elaborou seu próprio projeto de reconstrução para o MAM-RJ, que se insere em seu pensamento museológico da época. $\mathrm{O}$ assim chamado "Museu das origens" deveria, mais do que um museu de arte moderna, ser uma plataforma cultural em sentido mais amplo, abarcando não apenas a arte moderna nacional e internacional, mas também a produção negra, indígena, popular e "virgem", como chamava a produção reunida no Museu do Inconsciente. Segundo Pedrosa (1978b, s/p), "na fundação do Museu das origens prevê-se o estabelecimento de cinco museus [...] afins embora independentes entre si”: Museu do Índio; Museu da Arte Virgem (Museu do Inconsciente); Museu de arte moderna; Museu do Negro e Museu das Artes Populares. Essa proposta foi apresentada na reunião do Comitê Permanente pela Reconstrução do MAM, ocorrida no Parque Lage em 14 de setembro e publicada no Jornal do Brasil no dia seguinte, mas prontamente rejeitada pela direção do MAM-RJ, como apontado por Pollyana Quintella (2018, p. 44).

Dentro da visão de uma reconfiguração da historiografia das artes brasileiras é coerente a proposta que Pedrosa esboça para o que deveria compor o novo acervo de arte moderna dessa constelação de museus, reafirmando sua relação com a arte brasileira. O Museu de Arte Moderna proposto por Pedrosa deveria "reconstruir um acervo que seja antes de tudo representativo da arte brasileira", desde o impressionismo, com Eliseu Visconti, passando pelos modernistas da primeira geração como Victor Brecheret, Lasar Segall, Tarsila do Amaral, Anita Malfatti, Di Cavalcanti, Cândido Portinari, Alfredo Volpi, Osvaldo Goeldi e Lívio Abramo. Além disso, também deveria contemplar os artistas da época e as filiações internacionais da arte concreta brasileira, com uma sala de arte neoconcreta, como não poderia deixar de faltar (PEDROSA, 1978b, $\mathrm{s} / \mathrm{p})$. 
Cabe destacar também que o Museu do Negro e o de Artes Populares teriam relação direta com as populações ali inseridas. Assim, o Museu do Negro teria não apenas peças trazidas de África, mas também criadas no Brasil, "principalmente nos cultos religiosos, onde são usadas" (PEDROSA, 1978b, s/p). E o Museu de Artes Populares deveria ser composto por peças que representassem essa produção nas diversas regiões do país. A proposta do crítico, porém, não foi adiante, mas seria uma forma alternativa de encarar o futuro dos espaços museais e da própria arte, nos termos que apresentamos até aqui. Como afirma Sabrina Sant'Anna, o incêndio impôs duas possibilidades para a arte contemporânea, que representariam "percepções distintas" acerca de seu o futuro:

de um lado, a ênfase na experimentação se constituiria como principal esperança para os espaços expositivos. [...] De outro, a partir do diagnóstico [d]o esgotamento da sucessão de vanguardas, o turvamento de fronteiras entre alta e baixa cultura, arte popular e arte erudita, começaria a se colocar como possibilidade (SANT'ANNA, 2015, s/p).

Pedrosa, apesar de enfatizar o segundo projeto com seu "Museu das Origens" e não mencionar a Área Experimental, importante polo de atuação dos jovens artistas até o incêndio, parece buscar um equilíbrio entre os dois rumos apontados por Sant'Anna. O crítico tinha uma relação muito próxima com as propostas artísticas experimentais e estas eram parte de todo o debate sobre o esgotamento da arte moderna e suas possíveis saídas. Também é emblemático que Pedrosa tenha representado o "Museu das Origens" por meio de um diagrama no qual apresenta os cinco museus em círculo, demonstrando que não haveria qualquer hierarquia entre eles, e, ao centro, reunindo todos eles, estão as “atividades criativas e experimentais" (PEDROSA, 1978b, s/p).

Seriam tais atividades, portanto, que uniriam os cinco museus, traçando o plano no qual se daria a "contaminação híbrida entre matrizes culturais brasileiras" junto com a "contextualização sobre as imagens do inconsciente e da arte moderna" do qual nos falam Ivair Reinaldim e Michelle Sommer (2020, p. 102). Logo, o "Museu das Origens" seria uma maneira de trazer o passado à tona no presente, ampliando o repertório artístico para aquelas produções que não tinham espaços à altura nos circuitos institucionais. Do mesmo modo, podemos dizer que essa estrutura do "Museu das 
Origens" é coerente com o pensamento museológico de Pedrosa dentro de sua defesa pela “opção terceiro-mundista” para um país como o Brasil.

Esse pensamento de Pedrosa, no entanto, também já havia sido esboçado anteriormente. Em 1958, em carta a Oscar Niemeyer a respeito da criação de um Museu de Arte Moderna em Brasília, o crítico expõe sua opinião sobre a criação de museus com acervos internacionais em um país como o Brasil. Em primeiro lugar, critica os acervos modernistas já existentes em São Paulo e no Rio de Janeiro, a despeito dos esforços de seus criadores, por vê-los como um gasto enorme de dinheiro que resultaria em coleções sempre incompletas. Em Brasília a situação seria ainda pior, já que estaria afastada dos centros intelectuais do país e permaneceria em formação por muitos anos. O Pedrosa, porém, dá um salto ao pensar o museu não como um repositório de obras-primas, mas sim como uma instituição cultural e educativa - um "instituto de artes" em suas palavras. Para ele, o museu de Brasília deveria ser suis generis e atender a objetivos de ordem educacional e documental, por meio de reproduções e maquetes de obras históricas que representassem a história da arte. Assim, não competiria com outros museus nacionais e internacionais, mas ao mesmo tempo seria o mais completo de todos, sem as lacunas que seriam impossíveis de serem preenchidas por meio da aquisição de obras originais.

\begin{abstract}
Nele não haverá falhas e omissões quanto a escolas e estilos do passado, às manifestações artísticas das diversas civilizações e culturas históricas e aos diversos movimentos que definem a arte contemporânea. O museu será traçado de forma a dar ao público a exata curva da evolução criadora e artística da humanidade, desde a arte das cavernas pré-históricas até a arte de nossos dias. Tudo o que é representativo de cada época, de cada cultura e civilização, de cada escola estará presente no museu. ${ }^{6}$
\end{abstract}

Como podemos perceber, seu pensamento é essencialmente historiográfico, mas ao mesmo tempo busca acolher todas as principais culturas humanas, ocidentais e orientais, como exposto no "roteiro expositivo" que apresenta ao arquiteto de Brasília. Podemos notar, porém, que os povos indígenas brasileiros não estão presentes na lista dos "ciclos históricos" que o museu deveria abranger. Na lista de "civilizações précolombianas" vemos apenas a Maia, a Asteca e a Inca, enquanto que os indígenas

\footnotetext{
${ }^{6}$ Carta de Mário Pedrosa a Oscar Niemeyer datada de 24 de julho de 1958
} 
brasileiros estariam junto a outros "povos primitivos contemporâneos" da África, da Polinésia e das Américas. É sintomático vermos como o crítico ainda relegava a produção indígena ao passado folclórico do país, fora das questões contemporâneas de uma civilização tropical que erigia em meio ao cerrado sua monumental capital modernista. Desse modo, também é possível compreender seu entusiasmo em relação à construção de Brasília em solo "virgem" por meio de um esforço heroico equiparável ao dos colonizadores portugueses. De todo modo é possível indicar que apesar das questões indígenas não ressoarem no presente histórico da inauguração de Brasília elas se fazem presentes por meio da inserção dessas culturas no museu a ser criado. Assim, vemos como há um esforço - semelhante àquele que levou à criação do Museu do Índio - em se preservar aquelas culturas que estavam ameaçadas de extinção pelas políticas desenvolvimentistas nacionais.

Dois anos depois Pedrosa iria aprofundar sua ideia de um museu para aquela contemporaneidade, em sintonia com desdobramentos que apenas ficariam evidentes na produção artística dos anos subsequentes. Em “Arte experimental e museu”, o crítico afirma que o museu "de hoje é, sobretudo, uma casa de experiências. É um paralaboratório. É dentro dele que se pode compreender o que se chama de arte experimental, de invenção" (PEDROSA, 1960, p. 2). Na alvorada da diluição das fronteiras dos meios artísticos, Pedrosa advogava por um museu que abrigasse as experiências artísticas da sua época, cada vez mais realizadas no espaço. Sua proposta baseava-se também na observação e acompanhamento atento das práticas artísticas ligadas ao neoconcretismo de um "fazer experimental" e o museu deveria, ser "o sítio privilegiado onde essa experiência se deve fazer e decantar" (idem).

\subsection{Crise política: o Museu da Solidariedade Salvador Allende}

Iremos agora nos dirigir a um evento ocorrido alguns anos antes das propostas de "Alegria de viver, Alegria de criar" e do "Museu das Origens", mas que informa essas duas experiências. Em 1970, Pedrosa teve que fugir novamente do Brasil, pois estava sendo perseguido pelo governo militar, e se exilou no Chile, então sob o governo socialista da Unidad Popular de Salvador Allende. Rapidamente integrou-se nas 
instituições artísticas locais, passando a dar aulas no Instituto de Arte Latinoamericano (IAL) da Universidade do Chile. Em 1971 o governo de Allende, frente à dificuldade em se contrapor à narrativa dos meios de comunicação hegemônicos nacionais e internacionais, organizou a Operación Verdad, um "convite massivo a intelectuais, artistas, ativistas e políticos progressistas de todo o mundo para 'que percorressem o país sem travas e nem guias de amabilidade opressiva”" (BERRÍOS, 2017, p. 89).

Entre os visitantes estava o crítico de arte espanhol José María Moreno Galván que pensou na possibilidade de se criar um "Museu de Arte Moderna e Experimental", com doações de artistas do mundo todo em apoio ao processo político chileno. Alguns meses depois, o próprio Allende escreveu a Galván pedindo que acelerasse a criação do museu para inaugurá-lo na abertura da Conferência das Nações Unidas sobre Comércio e Desenvolvimento III (UNCTAD III), que seria realizada em Santiago no ano seguinte. Para tanto foi criado o Comitê Internacional de Solidariedade Artística com Chile (C.I.S.A.C.), reunindo importantes nomes da cena artística internacional, como Dore Ashton, Giulio Carlo Argan e Louis Aragon, entre outros, tendo Pedrosa como diretor. O C.I.S.A.C. tinha como objetivo de criar uma rede para buscar doações de artistas do mundo todo e conseguiu apoio de diversas personalidades internacionais, como Harald Szeemann, então curador da Documenta 5, realizada em 1972, que contatou todos os artistas com os quais já estava trabalhando para a exposição alemã (MACCHIAVELLO, 2016, p. 34).

Rapidamente as obras foram chegando e em maio de 1972 a coleção já contava com mais de 400 trabalhos de artistas de renome de diversos países. A obra mais emblemática era a pintura de um galo doada por Joan Miró, que se tornou símbolo dessa coleção pouco coerente, porém reunida sob o signo da solidariedade ao projeto socialista de Allende. Segundo Berríos (2017, pp. 96-97), em 1973 a coleção já possuía cerca de "8oo obras, com valor estimado em 8 milhões de dólares", valor maior que "o gasto direto do regime de Nixon para desestabilizar o Chile no mesmo período". O museu foi rebatizado como Museu da Solidariedade e foi aberto ao público, em maio de 1972, junto à UNCTAD III.

Com o golpe militar liderado pelo general Augusto Pinochet, em setembro de 1973, o museu foi fechado e suas obras supostamente desapareceram - a maioria foi 
escondida no subsolo do Museu de Arte Contemporânea de Santiago e só voltou à luz depois da queda do regime de Pinochet. O Museu da Solidariedade tornou-se então um programa verdadeiramente internacional como Museu Internacional da Resistência Salvador Allende (MIRSA) e núcleos foram criados ao redor do mundo - em 1979 existiam representações do MIRSA em Cuba, México, Venezuela, Panamá, Colômbia, França, Espanha, Suécia, Finlândia e Polônia, além de uma seção africana que seria inaugurada logo depois (MACCHIAVELLO, 2016). Apenas em 1991 a coleção voltou a ser exposta em Santiago e ganhou sede própria e seu nome atual, Museu da Solidariedade Salvador Allende (MSSA).

Na "Declaração Necessária” divulgada pelos membros do C.I.S.A.C., em novembro de 1971, estão expostos alguns pontos importantes na relação entre arte e política que estava sendo gestada ali. Para além da necessidade em se organizar a solidariedade dos "artistas do mundo" com a "via chilena para o socialismo", o projeto do Museu da Solidariedade girava em torno da ideia de política "no mais alto sentido do termo, quer dizer, em um sentido eminentemente ético, humanista e libertário" (apud LEAL, 2018, p. 186). Havia ainda a aspiração dos artistas de que suas obras não ficassem “confinadas nas áreas metropolitanas dos países ricos e avançados do hemisfério norteocidental, mas antes que cheguem em profusão às grandes áreas desprivilegiadas do Terceiro Mundo" (idem). Também Allende, ao agradecer a solidariedade dos artistas que doaram suas obras, afirma que seria o primeiro museu "em um país do Terceiro Mundo" no qual, "por vontade dos próprios artistas, aproximará as mais elevadas manifestações da plástica contemporânea às grandes massas populares" (ALLENDE apud LEAL, 2018, p. 189). De fato, calcula-se que mais de cem mil pessoas visitaram a exposição, um número extraordinário para o Chile (BERRÍOS, 2017, p. 95).

\subsection{A diluição das fronteiras entre arte "culta" e arte "popular"}

A criação do Museu da Solidariedade também deve ser vista em um movimento mais amplo da política cultural de Allende, que inclusive estava em seu programa de governo (ZOLI, 2011, p. 232). Havia ainda a busca por reparar as injustiças históricas cometidas contra o povo Mapuche e pela criação e fortalecimento das cooperativas de 
artesãos do país e suas cadeias econômicas. Pedrosa esteve bastante próximo dessa construção, tanto que a relatou em conferência realizada no México em 1975, intitulada "Arte culta e arte popular". Novamente o crítico busca descrever historicamente a inserção da arte na sociedade ocidental para chegar ao impasse da arte moderna na sociedade capitalista daquele momento. Segundo Pedrosa, a "arte erudita" seria uma forma de "mistificação cultural”, reproduzindo e projetando essa

\footnotetext{
mistificação como os bens supremos que os grandes monopólios das multi, ou melhor, transnacionais levam para todo o mundo, principalmente para os países da periferia" como "os símbolos da civilização cosmopolita do global shopping center a que os sumos sacerdotes das gigantescas empresas monopolistas querem reduzir o planeta (PEDROSA, 1980, p. 24, grifos do autor).
}

O artesanato poderia então ser "revolucionariamente valioso" caso contribuísse "para romper a estrutura de classes" e para colocar "em questão o monopólio da atividade criadora da burguesia”. Essa teria sido a experiência impulsionada no governo de Allende, que reforçou as iniciativas já existentes de cooperativas de artesãos, como a Cooperativa Centro de Mães, que servia de intermediária entre as artesãs e o comércio na capital chilena, permitindo não só a popularização dessa produção, mas "também a criação de numerosas pequenas indústrias e a incorporação, em forma de centros de mães ou comunidades de bairros, de novos setores à produção" (PEDROSA, 1980, p. 24). Assim, não só o artesão pôde se dedicar exclusivamente ao seu trabalho, sem se preocupar com sua comercialização, mas também a redistribuição de renda promovida pelo governo Allende criou um novo mercado consumidor que podia agora comprar essas peças artesanais, contribuindo para a "desalienação do 'gosto" entre os setores populares. Isso se dava pois, aos poucos, essa produção artesanal ia substituindo, nas paredes das "casas da pequena burguesia e nos lares proletários [...] as más reproduções e as folhas de calendário", assim colaborando "para a formação de um novo ambiente plástico íntimo para o chileno" (PEDROSA, 1980, p. 25).

Essa ideia de um novo "ambiente plástico" é bastante interessante de ser pensada à luz do que viemos debatendo sobre a arte ambiental nos artistas experimentais, levando agora à criação de um ambiente plástico para a população em 
geral e assentado na experiência cultural local, fomentando todo um circuito de arte popular. Outra importante transformação social identificada por Pedrosa no processo político-cultural chileno é a do papel da mulher na produção artesanal que, além de encontrar uma atividade que a liberava do trabalho doméstico nas casas da burguesia para complementar a renda familiar, também ganhava "um prestígio que afirma sua situação no lar, assim como no interior do grupo local e familiar" (PEDROSA, 1980, p. 26).

Outro ponto destacado por Pedrosa é a diluição entre as fronteiras da "alta” e da "baixa" cultura no processo econômico e cultural chileno, pois com a ampliação da produção artesanal fomentada pelas políticas públicas do governo de Allende, cresce também o interesse da burguesia por essa produção. Assim, "a distinção entre artesão e artista se desvanece e o artesão assume a condição social de artista" e as universidades também passam a integrar o artesanato em seus currículos, fazendo com que os artistas desçam "de seu pedestal" já que o artesanato passa a ser visto como "uma atividade tão importante como a pintura ou a escultura” (PEDROSA, 1980, p. 26).

Ocorre ainda a transformação do artesanato de "souvenir para turista" em decoração das casas da burguesia que passam a cultivar "uma identificação nacional ou latino-americana” e, finalmente, as cadeias produtivas locais também se tornam espaços de confraternização e discussões políticas da comunidade, tendo um impacto social e cultural muito mais amplo (PEDROSA, 1980, p. 26). Podemos ver, portanto, como essa “descoberta” da arte popular e seus mecanismos de produção por Pedrosa se aliam à sua visão sobre as artes de modo geral e o impasse que ele identificava, pois a hibridização entre a arte popular e a erudita seria outra maneira de afirmar seu caráter experimental e também de impulsionar sua renovação, assim como Oiticica havia descoberto seu veio experimental no morro da Mangueira.

Vemos aqui se conjugar toda a trajetória política e cultural de Pedrosa, unindo arte, cultura e política de uma vez. Em conferência proferida no IAL em 1971, Pedrosa dá a ver seu pensamento em torno dessa relação, definindo o papel fundamental que a cultura deveria ter na luta pelo socialismo. Segundo Pedrosa (2017, p. 134), "em sua essência a luta pelo socialismo é a luta pela cultura" e esta não deveria se limitar a "meras propagandas partidárias mas alcançar todos os problemas implícitos e explícitos 
concernentes à implantação do socialismo em nosso país", devendo envolver todos os artistas, tanto os já atuantes, quanto aqueles que "estão por ser formados no seio do povo, solicitados por milhares de chamados, gerando milhares de iniciativas. Não é isso a revolução?"

O crítico segue com o raciocínio da eliminação das barreiras entre "alta” e "baixa” cultura como exposto em "Arte culta e popular", mas trazendo para o contexto político e social da revolução socialista. Por fim, vemos novamente Pedrosa explorando possíveis saídas para o impasse colocado à produção artística ocidental e sua relação tanto com a economia capitalista quanto com as produções dos povos "primitivos" ou dos artesãos. Para ele, deveriam ser recriadas "as condições para que a arte seja outra vez como nas épocas remotas, nas velhas sociedades pré-capitalistas, uma necessidade coletiva, o que hoje, sobretudo nas sociedades de economia de mercado não o é, sendo simplesmente uma atividade elitista" (PEDROSA, 2017, p. 136).

Vemos, portanto, que o crítico depositava grandes esperanças na transformação socialista pela qual o Chile estava passando e a via como uma possibilidade prática para a política dos países periféricos de modo geral e também como um indicador para os rumos culturais da humanidade, que floresceria justamente por meio de políticas socialistas nos países do chamado terceiro mundo. Aqui vemos também a emergência do pensamento do crítico em relação ao contexto de produção da arte indígena que mencionamos anteriormente. Seja a produção indígena ou a popular, Pedrosa se interessa menos por suas características formais do que pelo seu contexto de produção, que deveria servir de farol para os artistas experimentais de sua época.

Neste sentido, o processo político cultural chileno parece ter tido grande impacto no pensamento de Pedrosa em meio à sua visão do esgotamento da arte moderna, e da própria arte de modo geral, e reforça sua opção pelos países do chamado terceiro mundo como potenciais renovadores da linguagem artística. Em seu importante “Discurso aos Tupiniquins ou Nambás”, escrito em Paris no ano de 1975, Pedrosa (1976, p. 40) afirma que nos países centrais a arte perdera completamente sua "autonomia existencial e naturalmente espiritual” e que já não seriam "sociedades propícias ao desenvolvimento do fenômeno artístico". Já os países ao sul do Equador, onde "o que é natureza já é cultura e o que é cultura ainda é natureza”, deveriam traçar seus próprios 
caminhos de desenvolvimento econômico e "expulsar de seu seio a mentalidade 'desenvolvimentista', que é a barra em que se apoia o espírito colonialista”. Frente ao "beco sem saída" no qual a "civilização burguesa imperialista" se encontrava, novos caminhos teriam que ser abertos pelos países do terceiro mundo: "deste beco não temos que participar - os bugres das baixas latitudes e adjacências”.

Os países periféricos deveriam, portanto, inventar suas próprias trajetórias para saírem desse "beco sem saída", já que até ali a imitação de modelos do norte global nos haviam legado apenas a miséria.

Os ultramodernismos e alguns de seus progressos, de molde comumente americano, estão umbilicamente vinculados a nossas favelas e barriadas. $\mathrm{O}$ paradoxo é que estas são as que não mudam, como não mudam a miséria, a fome, a pobreza, choças e ruínas. Mas é por aí que passa o futuro. Aqui está a opção do Terceiro Mundo: um futuro aberto ou a miséria eterna (PEDROSA, 1976, p. 40, grifos nossos).

Como coloca Carmen Palumbo (2018, p. 135), neste texto Pedrosa afirma sua “opção terceiro-mundista" que se tornaria "projeto político, no qual a abolição do neocolonialismo implantado com a ditadura militar seria possível apenas com um projeto socialista democrático, em ruptura com o estado burguês". Conjugam-se, portanto, as questões sociais e artísticas que vinham mobilizando o crítico havia algumas décadas e que aqui analisamos. E essa "opção terceiro-mundista” seria também o que levaria Pedrosa a pensar na elaboração da exposição “Alegria de viver, Alegria de criar”, como produção do sul para o sul global.

\section{Considerações finais}

Como pudemos ver, Mário Pedrosa, em sua longa trajetória crítica, curatorial e política, buscou dar respostas aos principais impasses sociais e estéticos de seu tempo, sintonizando mudanças que inclusive ainda demorariam alguns anos a se consolidarem. Assim, acompanhamos três momentos emblemáticos da última década de sua vida, nos quais ele busca responder a diferentes crises que se colocavam diante dele. Do mesmo modo, pudemos acompanhar algumas reviravoltas em seu pensamento, principalmente 
em relação à produção indígena, fruto também de sua sensibilidade às urgências sociais de seu tempo e da estreita colaboração com os artistas. Como afirma Adele Nelson, a visão de Pedrosa

\begin{abstract}
das instituições artísticas se encontra indissociavelmente ligada à evolução de sua ideia de arte em geral. Em particular, o processo de ampliação e reformulação de sua imagem da modernidade, que se prolongou desde os anos quarenta até os setenta, não se pode entender completamente sem ter em conta a mudança paralela de suas proposições museológicas e curatoriais (NELSON, 2017, p. 55-56).
\end{abstract}

Assim, os esforços de ampliação do campo artístico e político que vimos nas produções de Pedrosa aqui abordadas, revelam uma nova postura diante da produção artística de seu tempo, substituindo "a narrativa eurocêntrica por um relato global no qual a criatividade não era domínio exclusivo dos artistas, mas formava parte de uma herança mais ampla, comum a toda humanidade" (NELSON, 2017, p. 56). Como também coloca Pollyana Quintella (2018, p.18), o crítico buscava "garantir o aspecto universalista da arte", daí advindo "a possibilidade de inserir as experiências artísticas não ocidentais dentro de dispositivos de legitimação artística” como os museus. E sua inequívoca “opção terceiro-mundista” era o caminho a ser perseguido para conquistar essa nova narrativa em nível global. Seguimos perseguindo esse farol lançado por Pedrosa há mais de quarenta anos e que parece sempre atual à luz das tragédias e impasses políticos, estéticos, patrimoniais e ambientais que teimam em assolar nossa sociedade rotineiramente.

\title{
Referências
}

A CAMPANHA pelo MAM. Tribuna da Imprensa. Rio de Janeiro, 18 jul. 1978. p. 10

BERRÍOS, María. Por el futuro artístico del mundo. Mário Pedrosa y el Museo de la Solidaridad. In: PÉREZ-BARREIRO, Gabriel; SOMMER, Michelle Farias (orgs.). Mário Pedrosa - De la naturaleza afectiva de la forma [catálogo de exposição]. Madrí: Museu Nacional Centro de Arte Reina Sofia, 2017, p. 86-101.

GOGAN, Jessica (org.); MORAIS, Frederico. Domingos da criação: uma coleção poética do experimental em arte e educação. Rio de Janeiro: Instituto MESA, 2017. 
INCÊNDIO destrói todo acervo do MAM. Jornal do Brasil. Rio de Janeiro, o9 jul. 1978. p. 01

LEAL, André. Espaço-corpo, ambiente-experiência: Hélio Oiticica e Gordon Matta-Clark - genealogias do 'contemporâneo' [dissertação de mestrado]. 2015. 205 fls. Rio de Janeiro: Programa de Pós-Graduação em Artes Visuais da Escola de BelasArtes/UFRJ.

2018. Por museus da solidariedade. Arte \& Ensaios, Rio de Janeiro, ano XXIII, $\mathrm{n}^{\circ}$ 36, p. 179-191.

LOPES, Fernanda. Área experimental: lugar, espaço e dimensão do experimental na arte brasileira dos anos 1970. São Paulo: Prestígio editorial, 2013.

MACCHIAVELLO, Carla. Un caso de resistencia colectiva: el Museo de la Solidaridad Salvador Allende. In: A los artistas del mundo... Museo de la Solidaridad Salvador Allende, México/Chile 1971-1977 [catálogo de exposição]. Cidade do México: Editorial RM, 2016, p. 26-69.

NELSON, Adele. Mario Pedrosa, el museo de arte moderno y sus márgenes. In: PÉREZBARREIRO, Gabriel; SOMMER, Michelle Farias (orgs.). Mário Pedrosa - De la naturaleza afectiva de la forma [catálogo de exposição]. Madrí: Museu Nacional Centro de Arte Reina Sofia, 2017, p. 54-63.

PAPE, Lygia. Catiti Catiti na terra dos Brasis [dissertação de mestrado]. 1980. 104 fls. Rio de Janeiro: Programa de Pós-Graduação em Filosofia do Instituto de Filosofia e Ciências Humanas/UFRJ.

PEDROSA, Mário. Arte, necessidade vital. Correio da Manhã. Rio de Janeiro, 13 e 20 abril 1947. s/p

. Nuvens sobre Brasília. Jornal do Brasil. Rio de Janeiro, 13 maio 1958. p. 6

. Brasília, a cidade nova. Jornal do Brasil. Rio de Janeiro, 19 set. 1959. p. 3

Arte experimental e museu. Jornal do Brasil. Rio de Janeiro, 16 dez. 196o. p. 2

Arte ambiental, arte pós-moderna, Hélio Oiticica. Correio da Manhã. Rio de Janeiro, 26 jun. 1966a. s/p 1966b. p.10

Crise do condicionamento artístico. Correio da Manhã. Rio de Janeiro, 31 jul.

Mundo em crise, homem em crise, arte em crise. Correio da Manhã. Rio de Janeiro, 24 dez. 1967. p. 3 
- Arte dos Caduceus, arte negra, artistas de hoje. Correio da Manhã. Rio de Janeiro, 14 jan. 1968. p.4

. Discurso aos Tupiniquins ou Nambás. Versus, nº 4. São Paulo, 1976, p. 40.

. Escolha do crítico que cansou da vanguarda: a arte indígena [entrevista]. Jornal da Tarde. São Paulo, 31 dez. 1977. s/p

- Exposição Alegria de viver, Alegria de criar [manuscrito]. Coleção Mário Pedrosa, Biblioteca Nacional. Rio de Janeiro, 1978a. s/p

. Projeto Museu das Origens [manuscrito]. Coleção Mário Pedrosa, Biblioteca Nacional, 1978b. s/p

. Arte culta e arte popular. Arte em revista, no 3. São Paulo, 1980, p. 22-26.

Reflexões em torno da nova capital. Em: AMARAL, Aracy (org.). Mario Pedrosa:

Dos murais de Portinari aos espaços de Brasília. São Paulo: Ed. Perspectiva, 1981a. p. 303-316.

Arte não é fundamental. A profissão do intelectual é ser revolucionário [entrevista]. O Pasquim. Rio de Janeiro, 18 nov. 1981b. p. o7-11

. El modelo de Socialismo Chileno y el Frente del Arte. In: Pérez-Barreiro, Gabriel; Sommer, Michelle Farias (orgs.). Mário Pedrosa - De la naturaleza afectiva de la forma [catálogo de exposição]. Madrí: Museu Nacional Centro de Arte Reina Sofia, 2017. p. $132-136$

PÉREZ-BARREIRO, Gabriel. Sensibilizar la inteligencia: una introducción a la crítica de arte de Mário Pedrosa. In: Pérez-Barreiro, Gabriel; Sommer, Michelle Farias (orgs.). Mário Pedrosa - De la naturaleza afectiva de la forma [catálogo de exposição]. Madrí: Museu Nacional Centro de Arte Reina Sofia, 2017. p. 14-31

QUINTELLA, Pollyana Campos. Mário Pedrosa entre os tupiniquins ou nambás: uma perspectiva primitivista para a arte pós-moderna [dissertação de mestrado]. 2018. 109 fls. Rio de Janeiro: Programa de Pós-Graduação em Artes do Instituto de Artes/UERJ.

REINALDIM, Ivair; SOMMER, Michelle Farias. Experimentar o experimental: onde a pureza é um mi(s)to. In: REINALDIM, Ivair; SOMMER, Michelle Farias (orgs.). Experimentar o experimental: onde a pureza é um mi(s)to, furor da margem. Rio de Janeiro: Circuito, 2020. p. 87-107

SANT'ANNA, Sabrina Parracho. 2014. Presságios e projetos: o incêndio do MAM e os rumos da arte contemporânea. Revista VIS, Brasília, $n^{0}$ 13, v. 1., s/p 
SOMMER, Michelle Farias. Nós, os bugres das baixas altitudes e adjacências. In: REINALDIM, Ivair; SOMMER, Michelle Farias (orgs.). Experimentar o experimental: onde a pureza é um mi(s)to, furor da margem. Rio de Janeiro: Circuito, 2020. p. 109143

ZOLI, Ana Flávia. 2011. O Museu da solidariedade do Chile e Mário Pedrosa. Humanidades Em Diálogo, São Paulo, nº 4, v. 1, p. 231-243. 